\title{
Selective Removal of Phosphorus from Seawater Using Mechanochemical Treated Zircon Sand
}

\author{
K. Hirota and T. Wajima
}

\begin{abstract}
In this study, selective removal behavior of phosphorus from seawater using mechanochemical treated zircon sand was investigated. The product showed the same adsorption amount in seawater as that in the aqueous solution at pH 7, which means that phosphorus can be selectively adsorbed on the product in the solution with high salt concentration. The adsorption isotherm in seawater was found to applicable to Langmuir model rather than Freundlich model, and the calculated maximum adsorption amount was $0.01 \mathrm{mmol}$ $\mathrm{g}^{-1}$. The adsorption kinetics of the phosphorus in seawater fit much better to pseudo-second-order model than to pseudo-first-order model. Phosphorus can be recovered from deep seawater using the column. Chloride and sulfate are not affected to phosphorus removal, while carbonate ion affects on phosphorus removal of mechanochemical treated zircon sand.
\end{abstract}

Index Terms-Zircon sand, mechanochemical treatment, phosphorus removal, seawater, deep seawater.

\section{INTRODUCTION}

Phosphorus is discharged from agricultural soil and industrial wastewater to the surface water and the increase of phosphorus concentration in the surface water strongly contributes to eutrophication. Most of the phosphorus are drained into seawater, and phosphorus removal from seawater has received considerable attention.

Phosphorus is one of the important resources widely used such as agricultural fertilizer and metallic covering. Japan relies on $100 \%$ import of phosphorus ore as phosphorus resources and it is necessary to secure phosphorus resources in Japan. On the other hand, development of marine resources is an important issue in Japan because of an oceanic country surrounded by the sea on all sides. Deep seawater is generally under the depth of $200 \mathrm{~m}$ where sunlight cannot reach, and contains higher amounts of inorganic nutrient salts, such as nitrogen, phosphorus and silicon, and lower contamination by microorganisms and organic matter than surface seawater [1]. Development of deep seawater utilization for aquaculture, agriculture and so on is desired.

From these backgrounds, it is necessary to require method to remove and recover phosphorus from seawater with high salt concentration.

Several methods have been used to remove phosphorus from water, such as crystallization, coagulation precipitation, biological dephosphorization and adsorption [2]. Most of these methods are generally more suitable for the control of

Manuscript received November 12, 2019; revised March 15, 2020.

The authors are with the Department of Urban Environment Systems, Graduate School of Engineering, Chiba University, Japan (e-mail: seaturtle@chiba-u.jp,wajima@tu.chiba-u.ac.jp). high phosphorus concentration, and the control of low phosphorus concentration is relatively difficult. Adsorption is recommended for one of the most effective removal processes for the low concentration of phosphorus [3]. The adsorption ability of various substances for phosphorus, such as activated alumina, zirconium ( $\mathrm{Zr}$ ) based adsorbent, anion exchange resin and so on, is investigated [4]. Among them, zirconium-based adsorbent is known to have high selective removal for phosphorus from wastewater, because of the high chemical affinity of $\mathrm{Zr}-\mathrm{OH}$ to phosphorus $\left(\mathrm{H}_{2} \mathrm{PO}_{4}^{-}\right.$, $\mathrm{HPO}_{4}{ }^{2-}$ and $\mathrm{PO}_{4}{ }^{3-}$ ) [4]. Zirconium-based adsorbent, mainly zirconia, is prepared from zircon sand $\left(\mathrm{ZrSiO}_{4}\right)$ using wet-refining method, composed of alkali melting, water leaching, hydrochloric acid decomposition, concentration, washing, filtration, burning and milling, and this method needs a lot of energy to produce zirconium-based materials.

Mechanochemistry is the chemical phenomenon of giving mechanical energy to pulverize materials [5]. When pulverizing materials, a part of mechanical energy is consumed in irreversible work, such as lattice defect formation, the pulverized material is activated and the reactivity increases [5]. Therefore, mechanochemical treatment is used for the development of adsorbent materials by surface modification of particles. For example, there is a report for development of phosphorus adsorbent, calcium silicate, using mechanochemical treatment [6]. In previous study, highly selective phosphorus adsorbent could be prepared from zircon sand by simple mechanochemical treatment [7]. This adsorbent can be provided inexpensively and be used to remove phosphorus in high salt water, such as seawater. However, the details of phosphorus removal behavior in seawater have not been clarified.

In this study, the adsorbent with high selective phosphorus adsorption was prepared from inexpensive zircon sand by a simple mechanochemical treatment, and the phosphorus adsorption properties of the product in seawater, such as isotherm and adsorption ratio, are evaluated. In addition, we attempt to recover phosphorus from deep seawater using the obtained product.

\section{EXPERIMENT}

Raw zircon (zirconium silicate) used in this study was purchased from Wako Pure Chemical Industries, Ltd., Japan. Mechanochemical treatment was carried out using a planetary ball mill (P-6, Fritsch), and was carried out for 10 min using silicon nitride balls $(\varphi 5 \mathrm{~mm})$ and pot $(40 \mathrm{~mL})$ [7]. Seawater (SW) and deep seawater (DSW) used in this study were collected from the surface layer of Imari bay, Saga prefecture, Japan and Koshiki island, Kagoshima prefecture, 
Japan, respectively. The chemical compositions of SW and DSW are shown in Table I. It is noted that the $\mathrm{pH}$ of SW and DSW are 7.0 and 7.3, respectively.

TABLE I: CHEMICAL COMPOSITIONS OF SEAWATER (SW) AND DEEP SEAWATER (DSW)

\begin{tabular}{lccccccc}
\multicolumn{7}{c}{ SEAWATER (DSW) } \\
\hline \hline & $\mathrm{SO}_{4}{ }^{2-}$ & $\mathrm{Cl}^{-}$ & $\mathrm{Na}^{+}$ & $\mathrm{K}^{+}$ & $\mathrm{Mg}^{2+}$ & $\mathrm{Ca}^{2+}$ & $\mathrm{P}$ \\
\hline $\mathrm{SW}$ & 40.8 & 827 & 482 & 11.6 & 75.3 & 13.0 & - \\
$\mathrm{DSW}$ & 29.0 & 603 & 353 & 7.5 & 53.0 & 8.8 & 0.0017 \\
\hline \hline
\end{tabular}

Phosphorus adsorption isotherms in seawater and aqueous solution with $\mathrm{pH} 7$ were examined. It is noted that $\mathrm{pH}$ of the solution was adjusted using $\mathrm{NaOH}$ solution. $0.1 \mathrm{~g}$ of the product was added into $10 \mathrm{~mL}$ of seawater or aqueous solution with $0.05-0.5 \mathrm{mmol} \cdot \mathrm{L}^{-1} \mathrm{KH}_{2} \mathrm{PO}_{4}$, and was shaken for $12 \mathrm{~h}$. After shaking, the mixture was centrifuged. The equilibrium $\mathrm{pH}$ of supernatant was measured with the $\mathrm{pH}$ meter. The phosphorus concentration in the supernatant was determined by the molybdenum blue method to calculate the phosphorus adsorption amount and removal percentage using (1) and (2), respectively.

$$
\begin{aligned}
& q=\left(C_{0}-C\right) \cdot L / W \\
& \text { \% removal }=\left(C_{0}-C\right) / C_{0} \cdot 100
\end{aligned}
$$

where $q, C_{0}, C, W$ and $L$ are the adsorption amount, the initial phosphorus concentration, the phosphorus concentration after shaking, the weight of sample and the volume of solution, respectively.

The effect of coexisting ions on phosphorus adsorption by the product was investigated. $0.1 \mathrm{~g}$ of the product was added into $10 \mathrm{~mL}$ of $0.1 \mathrm{mmol} \cdot \mathrm{L}^{-1} \mathrm{KH}_{2} \mathrm{PO}_{4}$ solution with 1,10 and $100 \mathrm{mmol} \cdot \mathrm{L}^{-1}$ coexisting ions $\left(\mathrm{SO}_{4}{ }^{2-}, \mathrm{Cl}^{-}\right.$, and $\left.\mathrm{CO}_{3}{ }^{2-}\right)$ using $\mathrm{Na}_{2} \mathrm{SO}_{4}, \mathrm{NaCl}$ and $\mathrm{Na}_{2} \mathrm{CO}_{3}$, respectively, and was shaken for $3 \mathrm{~h}$. It is noted that the $\mathrm{pH}$ of solution containing $\mathrm{CO}_{3}{ }^{2-}$ was adjusted to 7 or 9 using hydrochloric acid to avoid the influence of $\mathrm{pH}$ on the adsorption. After shaking, the mixture was centrifuged, and the $\mathrm{pH}$ of supernatant was measured with the $\mathrm{pH}$ meter. The phosphorus concentration in the supernatant was determined by the molybdenum blue method to calculate the phosphorus adsorption amount using (1).

Phosphorus adsorption kinetics of the product in seawater was examined. $1.0 \mathrm{~g}$ of the product was added into $200 \mathrm{~mL}$ of seawater with $0.1 \mathrm{mmol} \cdot \mathrm{L}^{-1} \mathrm{KH}_{2} \mathrm{PO}_{4}$, and was stirred for $4 \mathrm{~h}$ at 10,20 and $40{ }^{\circ} \mathrm{C}$. During stirring, a part of the solution (2 $\mathrm{mL}$ ) was collected at each time, and was filtered using a membrane filter. The phosphorus concentration in the filtrate was determined by the molybdenum blue method to calculate the phosphorus adsorption amount using (1).

Phosphorus recovery from deep seawater using the product was carried out by column test (Fig. 1). The product was mixed with binder (PVA) and distilled water (product : binder : distilled water $=50: 1: 20$ ), the mixture was filled into the syringe, and form cylinder shape using the syringe. The cylinder was cut and dried using electric furnace to prepare cylinder-type granules (diameter $=2 \mathrm{~cm}$, length $=3$ $\mathrm{cm}$ ). The granules $(3 \mathrm{~g}$ ) was packed into column (filling ratio of $45.1 \%$ ) sandwiched between layers of glass wool, and distilled water was passed through the column before use. Deep seawater was then passed upward through the column at a flow rate of $5.0 \mathrm{~mL} \cdot \mathrm{min}^{-1}$, and was supplied to the column using a peristaltic pump. The effluent was collected using a fraction collector, and the phosphorus concentration in each fraction was determined by the molybdenum blue method to calculate the phosphorus adsorption amount using (1). (3)

The bed volume of the column, $B V$, was calculated using

$$
B V=v \cdot t / V
$$

where $v, t$ and $V$ are the flow rate of the solution $\left(\mathrm{mL} \cdot \mathrm{min}^{-1}\right)$, the time the feed solution was supplied ( $\mathrm{min}$ ), and the volume of the wet product $(\mathrm{mL})$, respectively.

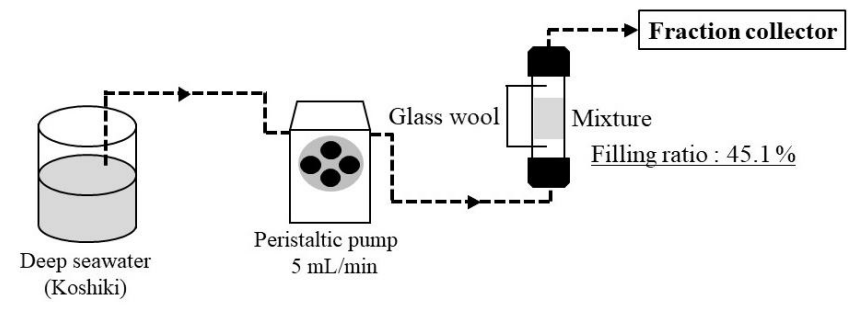

Fig. 1. Schematic of the adsorption column apparatus.

\section{RESUlTS AND DisCUSSION}

Fig. 2 shows the phosphorus adsorption isotherms of the product in seawater and aqueous solution at $\mathrm{pH}$ 7. The product indicates the same adsorption amount in seawater as that in aqueous solution, which means that the product can selectively adsorb phosphorus in seawater. The experimental results obtained in Fig. 2 was analyzed by Langmuir and Freundlich adsorption model to estimate the phosphorus adsorption behavior of the product in seawater.

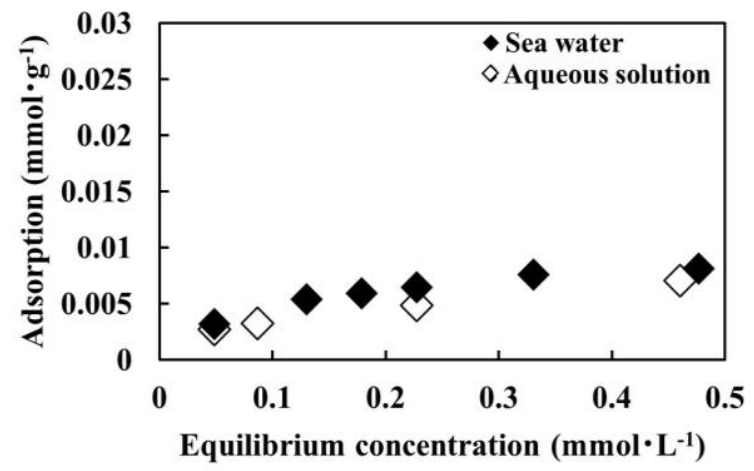

Fig. 2. Phosphorus adsorption amount of the product in seawater and aqueous solution.

The linearized equations of Langmuir and Freundlich adsorption models are as follows;

$$
\begin{aligned}
& C / q=\left(q_{\max } K_{\mathrm{L}}\right)^{-1}+C / q_{\max } \\
& \ln q=\ln K_{\mathrm{F}}+n^{-1} \cdot \ln C
\end{aligned}
$$

where $q_{\mathrm{max}}, K_{\mathrm{L}}, K_{\mathrm{F}}$ and $n$ are the maximum adsorption amount 
$\left(\mathrm{mmol} \cdot \mathrm{g}^{-1}\right)$, adsorption equilibrium constant of Langmuir model, and adsorption equilibrium constants of Freundlich model, respectively.

The results analyzed are shown in Table II. According to the correlation coefficient $\left(R^{2}\right)$, Langmuir equation can be more suitable than Freundlich equation for the phosphorus adsorption of the product in seawater.

TABLE II: THE RESULTS OF PARAMETERS FROM ADSORPTION ISOTHERM

\begin{tabular}{cccccc}
\hline & Langmuir & & \multicolumn{3}{c}{ Freundlich } \\
\hline$q_{\max }$ & $K_{\mathrm{L}}$ & $R^{2}$ & $n^{-1}$ & $K_{\mathrm{F}}$ & $R^{2}$ \\
\hline 0.01 & 8.94 & 0.997 & 0.413 & 0.0118 & 0.977 \\
\hline \hline
\end{tabular}

The important feature of the Langmuir isotherm can be written in form of a dimensionless quantity known as separator factor $\left(R_{\mathrm{L}}\right)$ which is given by $(6)$.

$$
R_{\mathrm{L}}=\left(1+K_{\mathrm{L}} C_{0, \max }\right)^{-1}
$$

where $K_{\mathrm{L}}$ and $C_{0, \max }$ are the adsorption equilibrium constant of Langmuir model and maximum initial concentration, respectively.

The value of $R_{\mathrm{L}}$ determines nature of the isotherm shape. It can either be favorable $\left(0<R_{\mathrm{L}}<1\right)$, unfavorable adsorption $\left(R_{\mathrm{L}}>1\right)$, liner $\left(R_{\mathrm{L}}=1\right)$ or irreversible adsorption $\left(R_{\mathrm{L}}=0\right)$. The obtained values of $R_{\mathrm{L}}$ to be 0.182 for phosphorus adsorption suggest that the process is favorable.

In addition, the value of the Freundlich constant $(n)$ indicates the affinity between the adsorbent and the adsorbate. The adsorbate is easily adsorbed $\left(0.1<n^{-1}<0.5\right)$, or difficulty adsorbed $\left(n^{-1}>2\right)$ [8]. The value of $n^{-1}$ obtained to be 0.413 for phosphorus adsorption suggest that the process has affinity.

The adsorption capacities of the adsorbents for the removal of the low phosphorus concentration have been compared with other kind of adsorbents, zirconium-loaded activated carbon, zirconium ferrite and cobalt adsorbent, reported in literatures (Table III). The adsorption capacity of the product for phosphorus is one-tenth higher than that of the other adsorbents.

TABLE III: THE COMPARISON OF ADSORPTION CAPACITY WITH OTHER

\begin{tabular}{ccccc}
\multicolumn{4}{c}{ ADSORBENTS } \\
\hline \hline Product & $\begin{array}{c}\text { Zirconium-loaded } \\
\text { activated carbon } \\
{[9]}\end{array}$ & $\begin{array}{c}\text { Zirconium } \\
\text { ferrite } \\
{[10]}\end{array}$ & $\begin{array}{c}\text { Cobalt } \\
\text { adsorbent }\end{array}$ \\
\hline $\begin{array}{c}\text { Adsorption } \\
\left(\mathrm{mmol} \cdot \mathrm{g}^{-1}\right)\end{array}$ & 0.01 & 0.125 & 0.116 & 0.176 \\
\hline \hline
\end{tabular}

Fig. 3 shows the phosphorus adsorption of product after mechanochemical treatment in seawater at various temperatures. As the stirring time increases, the phosphorus adsorption increased, and then gradually increased to be almost constant. As the temperature increases, the phosphorus adsorption amount increased.

The experimental results obtained in Fig. 3 were analyzed by pseudo-first-order and pseudo-second-order kinetics models to estimate the phosphorus adsorption behavior of the product in seawater.

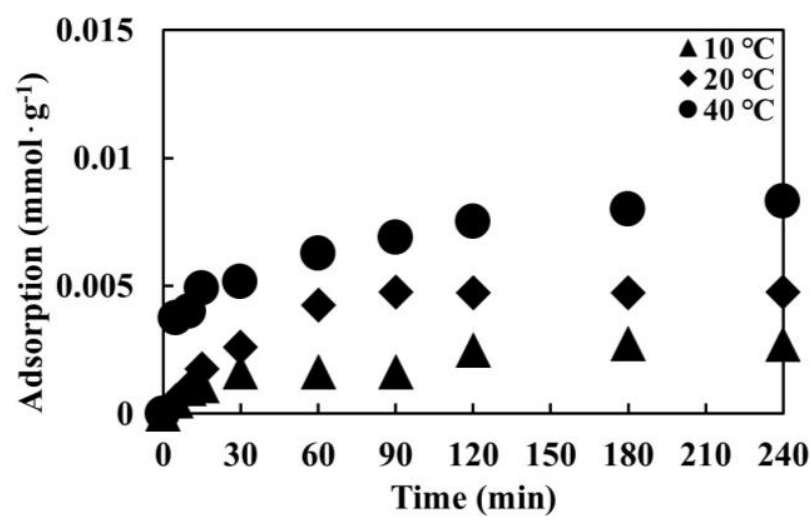

Fig. 3. Phosphorus adsorption of the product at various temperature.

The linearized equations of pseudo-first-order and pseudo-second-order kinetics models are as follows;

$$
\begin{aligned}
& \ln \left(q_{\mathrm{e}}-q_{\mathrm{t}}\right)=\ln q_{\mathrm{e}}-k_{1} \cdot t \\
& t / q_{\mathrm{t}}=\left(k_{2} \cdot q_{\mathrm{e}}{ }^{2}\right)^{-1}+t / q_{\mathrm{e}}
\end{aligned}
$$

where $q_{\mathrm{e}}, q_{\mathrm{t}}, k_{1}, k_{2}$ and $t$ are the maximum adsorption amount $\left(\mathrm{mmol} \cdot \mathrm{g}^{-1}\right)$, the adsorption amount at time $\left(\mathrm{mmol} \cdot \mathrm{g}^{-1}\right)$, the pseudo-first-order adsorption kinetics constant $\left(\mathrm{min}^{-1}\right)$, the pseudo-second-order adsorption kinetics constant $\left(\mathrm{g} \cdot \mathrm{mmol}^{-1} \cdot \mathrm{g}^{-1}\right)$, and time (min), respectively.

The results analyzed are shown in Table IV. According to the correlation coefficient $\left(R^{2}\right)$, the data fit much better to pseudo-second-order model than to pseudo-first-order model. It was found that the product has higher adsorption amount at higher the temperature, while reaction rates are almost same regardless of temperatures.

TABLE IV: THE RESULTS OF PARAMETERS FROM ADSORPTION KINETICS

\begin{tabular}{ccccccc}
\hline & \multicolumn{3}{c}{ Pseudo-first-order } & \multicolumn{3}{c}{ Pseudo-second-order } \\
\hline & $q_{\mathrm{e}}$ & $k_{1}$ & $R^{2}$ & $q_{\mathrm{e}}$ & $k_{2}$ & $R^{2}$ \\
\hline $10{ }^{\circ} \mathrm{C}$ & 0.00225 & 0.0084 & 0.807 & 0.00293 & 10.6 & 0.951 \\
$20{ }^{\circ} \mathrm{C}$ & 0.00348 & 0.0178 & 0.916 & 0.00535 & 6.91 & 0.984 \\
$40{ }^{\circ} \mathrm{C}$ & 0.00567 & 0.0125 & 0.964 & 0.00876 & 7.29 & 0.994 \\
\hline \hline
\end{tabular}

Fig. 4 shows the profile for the phosphorus adsorption from deep seawater using the product. The phosphorus concentration gradually increased and reached 0.0016 $\mathrm{mmol} \cdot \mathrm{L}^{-1}$ at $>1200$ bed volume. In the experiment, 0.000613 mmol of phosphorus was collected, which means that the product can recover about $30 \%$ phosphorus in deep seawater.

Fig. 5 shows the effect of coexistng ions $\left(\mathrm{SO}_{4}{ }^{2-}, \mathrm{Cl}^{-}\right.$and $\mathrm{CO}_{3}{ }^{2-}$ ) on the phosphorus adsorption by the product. The product indicates the same phosphorus adsorption amount in the solution with sulfate and chloride ions as those without coexisting solution, while phosphorus adsorption decreases in the solution with carbonate ion (40 - $60 \%$ decrease). 
Therefore, carbonate ion affects the adsorption of phosphorus by the product.

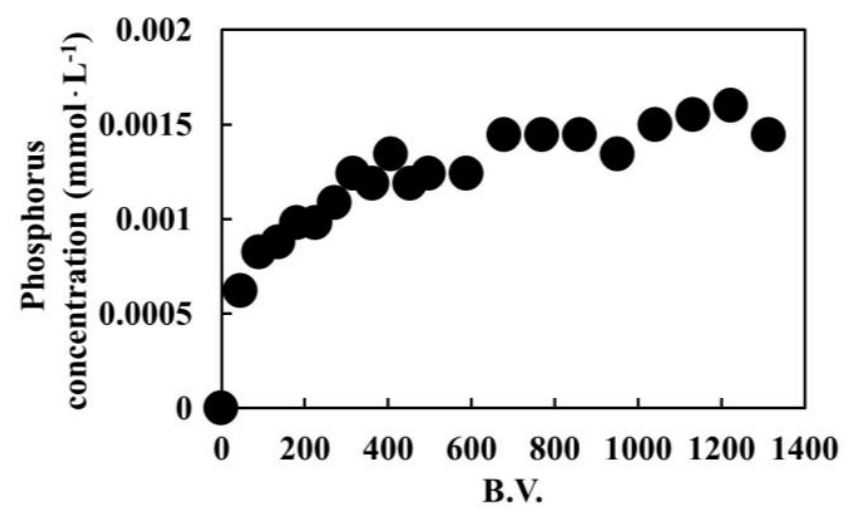

Fig. 4. The profile for the adsorption of phosphorus in deep seawater by the product using column (B.V. = bed volumes).
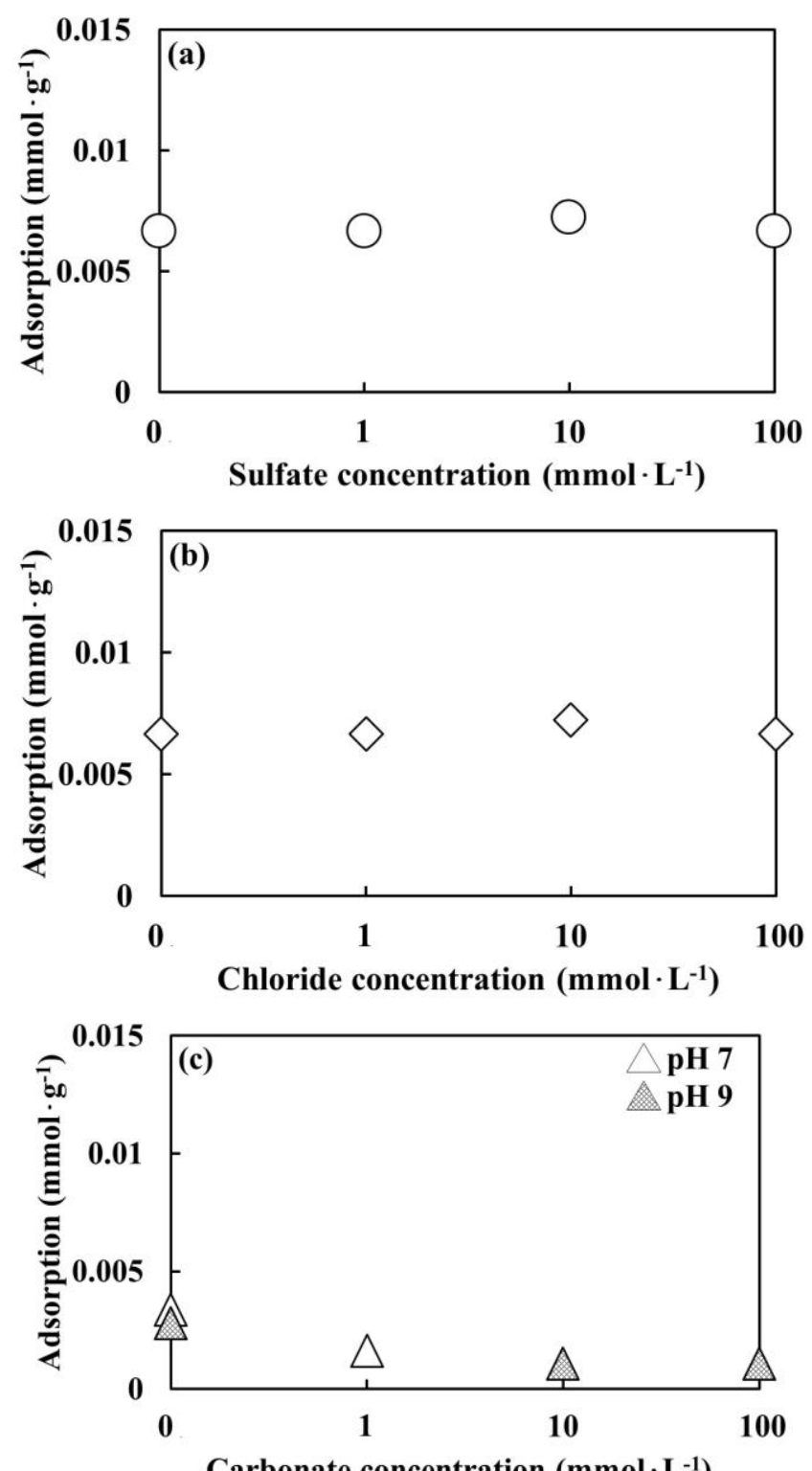

Fig. 5. Effect of coexisting ions ((a) $\mathrm{SO}_{4}{ }^{2-}$, (b) $\mathrm{Cl}^{-}$, (c) $\mathrm{CO}_{3}{ }^{2-}$ ) on phosphorus adsorption by the product.

\section{CONCLUSION}

It was attempted to investigate the removal behavior of phosphorus from seawater using mechanochemical treated zircon sand. As a result, the product can adsorb phosphorus selectively in the solution with high salt concentration. However, carbonate ions affect the adsorption of phosphorus using the product. The adsorption isotherm fit to Langmuir model better than Freundlich model. The calculated maximum adsorption amount was $0.01 \mathrm{mmol} \cdot \mathrm{g}^{-1}$. The obtained values of $R_{\mathrm{L}}$ to be 0.182 for phosphorus adsorption suggest that the process is favorable, and value of $n^{-1}$ obtained to be 0.413 for phosphorus adsorption suggest that the process has affinity. The adsorption kinetics of the phosphorus in the seawater fit to pseudo-second-order model better than pseudo-first-order model. The product indicates higher adsorption amount at higher temperature, while the reaction kinetics are almost same. The product can recover phosphorus from deep seawater using the column.

\section{CONFLICT OF INTEREST}

The authors declare no conflict of interest.

\section{AUTHOR CONTRIBUTIONS}

K. Hirota concuted the research, analyzed the data and wrote the paper, T. Wajima revised the manuscript and all authors had approved the final version.

\section{REFERENCES}

[1] K, Suzuki, "Deep sea water," Journal of the Society of Inorganic Material, Japan, vol. 12, pp. 423-428, 2005

[2] K. Urano, "Process development for removal and recovery of phosphorus in wastewater," Environmental Science, vol. 1, no. 3, pp. 99-114, Sept. 1998.

[3] S. Moharami and M. Jalali, "Removal of phosphorus from aqueous solution by Iranian naturaladsorbents," Chemical Engineering Journal, vol. 223, pp. 328-339, May 2013.

[4] B. K. Biswas, K. Inoue, K. N. Ghimire, H. Harada, K. Ohto, and H. Kawakita, "Removal and recovery of phosphorus from water by means of adsorption onto orange waste gel loaded with zirconium.," Bioresource Technology, vol. 99, pp. 8685-8690, Dec. 2008.

[5] Y. Okawauchi, K. Kuramitsu, and K. Makino, "Development of manganese dioxide as high efficient lithium adsorbent by mechanochemical treatments," Journal of the Society of Inorganic Materials, vol. 11, pp. 259-265, Sept. 2004

[6] H. Shiomi, H. Mukai, M. Masui, Y. Hashidume, and Y. Akita, "Development of phosphorous adsorbent using mechano-chemically treated calcium silicate," Journal of the Society of Material Science, Japan, vol. 53, no. 6, pp. 618-622, June 2004

[7] K. Hirota and T. Wajima, "Preparation of highly selective phosphorus adsorbent from zircon sand $\left(\mathrm{ZrSiO}_{4}\right)$ by mechanochemical treatment," Journal of Ion Exchange, vol. 29, no. 3, pp. 158-162, Sept. 2018.

[8] F. Ogata, H. Tominaga, M. Kangawa, K. Inoue, and N. Kawasaki, "Adsorption capacity of dye in the presence of dying assistant auxiliaries by carbonaceous material produced from cotton," Journal of the Surface Science Society of Japan, vol. 32, no. 12, pp. 804-808, Dec. 2011.

[9] T. Wajima, "Phosphorus adsorption on zirconium-loaded activated carbon, and application for phosphate recovery from deep seawater," International Journal of Chemical Engineering and Application, vol. 7, no. 6, pp. 388-393, Dec. 2016

[10] K. Hosomi, K. Shimizu and O. Miura, "Removal and recovery of phosphorus from wastewater using high-gradient magnetic separation applying a magnetic adsorbent," Journal of Cryogenics and Superconductivity Society of Japan, vol. 46, no. 11, 2011.

[11] H. Takamatsu, "Research on resource recovery of phosphorus recovered from wastewater using a new phosphorus adsorbent," Nagasaki Ceramic Technology Center Research Report, pp. 33-34, 2011. 
Copyright $(2020$ by the authors. This is an open access article distributed under the Creative Commons Attribution License which permits unrestricted use, distribution, and reproduction in any medium, provided the original work is properly cited (CC BY 4.0).

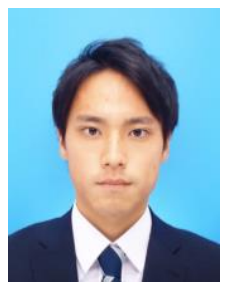

Kaito Hirota was born in June 1995 in Niigata Prefecture. He attends in the master's course of Department of Urban Environment Systems, Graduate School of Engineering, Chiba University, Japan.

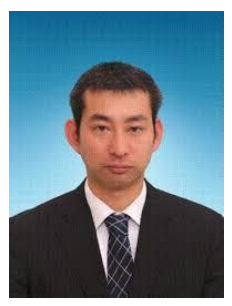

Takaaki Wajima was born in February 1976 in Saga Prefecture. He has been an associate professor in the Department of Urban Environment Systems, Graduate School of Engineering, Chiba University, Japan, Since 2013. He received his bachelor's degree and master's degree in resource engineering from Kyoto University, Japan, in 1998 and 2000, respectively, and his Ph.D in environmental mineralogy and technology from Kyoto University, Japan, in 2004. In 2004, he moved to the Institute of Ocean Energy at Saga University to work as a postdoctoral researcher, and 2007 to 2013 he was an Assistant professor at Akita University, Japan. His main research interests are waste recycling, resource recovery, and environmental purification. 